\title{
DETERMINAÇÃO VOLTAMÉTRICA DE METAIS EM ÁGUAS E FLUIDOS BIOLÓGICOS EMPREGANDO MINERALIZAÇÃO DE AMOSTRAS COM RADIAÇÃO ULTRAVIOLETA ${ }^{\#}$
}

\author{
Leandro M. de Carvalho*, Cristiane Spengler, Júlia C. Garmatz, Paulo C. do Nascimento, Denise Bohrer, Luciana Del- \\ Fabro, Guilherme Radis e Antônio A. Bolli \\ Departamento de Química, Universidade Federal de Santa Maria, CP 5051, 97110-970 Santa Maria - RS, Brasil \\ Solange C. Garcia e Angela M. Moro \\ Departamento de Análises Clínicas e Toxicológicas, Universidade Federal de Santa Maria, 97110-970 Santa Maria - RS, Brasil \\ Marcelo B. da Rosa \\ Laboratório de Exobiologia e Biosfera, Centro Regional Sul de Pesquisas Espaciais, 97110-970 Santa Maria - RS, Brasil
}

Recebido em 14/5/07; aceito em 11/1/08; publicado na web em 31/7/08

\begin{abstract}
VOLTAMMETRIC DETERMINATION OF METALS IN WATERS AND BIOLOGICAL FLUIDS USING SAMPLE MINERALIZATION WITH ULTRAVIOLET RADIATION. This work describes the optimization of pretreatment steps for the destruction of organic matter in samples of waters and biological fluids, by using an UV irradiation system with a high power UV radiation source $(400 \mathrm{~W})$. The efficiency of the system constructed for the photo-decomposition of samples of model waters, natural waters and biological fluids was investigated by performing recovery experiments of the metallic species $\mathrm{Zn}$ (II), $\mathrm{Cd}(\mathrm{II}), \mathrm{Pb}$ (II), $\mathrm{Cu}$ (II), $\mathrm{Al}(\mathrm{III})$ and $\mathrm{Fe}(\mathrm{III})$. The use of UV irradiation allowed the liberation of metals bound to the organic matrix and the determination of the total content of elements in the samples.
\end{abstract}

Keywords: stripping voltammetry; sample mineralization; UV radiation.

\section{INTRODUÇÃO}

As técnicas voltamétricas de redissolução anódica (ASV) e de redissolução catódica (CSV), por serem de grande sensibilidade e seletividade, são cada vez mais empregadas na determinação de metais presentes em diferentes matrizes. ${ }^{1,2}$ Entretanto, a presença da matéria orgânica em análises voltamétricas pode comprometer a determinação da concentração de metais devido à formação de complexos estáveis e inertes à detecção. Além disso, a matéria orgânica pode competir com a espécie de interesse pela superfície do eletrodo de trabalho, reduzindo assim a sensibilidade da medida e provocando o aparecimento de sinais interferentes. ${ }^{3}$ A própria matéria orgânica pode, ainda, sofrer redução ou oxidação eletroquímica, aumentando a corrente residual a ponto de impedir a execução da análise. Por esta razão, a etapa de pré-tratamento da amostra para a eliminação da interferência orgânica é de grande importância na análise voltamétrica.

O método clássico para a destruição da matéria orgânica dissolvida é a mineralização por via úmida, que emprega o aquecimento da amostra e adição de reagentes como ácidos oxidantes ou misturas destes ou, ainda, peróxido de hidrogênio $\left(\mathrm{H}_{2} \mathrm{O}_{2}\right)$. Porém, estes métodos apresentam a desvantagem de oferecer um alto risco de contaminação da amostra, principalmente no caso de amostras que contêm metais no nível de traço, ${ }^{4}$ além de requererem um grande consumo de reagente e um longo tempo de mineralização. Sendo assim, uma alternativa à mineralização ácida é a mineralização empregando irradiação ultravioleta (UV) que, além de ser eficiente, minimiza a possibilidade de contaminação da amostra devido ao uso de pequenas quantidades de ácidos e peróxido de hidrogênio.

As reações fotoquímicas são geralmente de tipo radicalar e baseiam-se na formação do radical hidroxila $(\mathrm{HO} \bullet)$, um agente

*e-mail: leandrocarvalho@smail.ufsm.br

\#Este artigo é dedicado ao Sr. Antônio Augusto Bolli pelos seus 80 anos de vida, criatividade, inventividade e dedicação ao trabalho. oxidante altamente reativo capaz de romper ligações de caráter covalente e induzir a mineralização completa dos compostos orgânicos presentes na amostra. Além disso, este procedimento proporciona uma redução significativa no tempo de mineralização e nas quantidades de reagentes empregados. ${ }^{5}$

A fotólise do $\mathrm{H}_{2} \mathrm{O}_{2}$ e da $\mathrm{H}_{2} \mathrm{O}$ pela radiação UV gera os radicais hidroxila (reações 1 e 2) que agem degradando a matéria orgânica e formando compostos minerais mais simples (reação 3) como produtos finais de degradação. ${ }^{6-8}$

$$
\begin{aligned}
& \mathrm{H}_{2} \mathrm{O}_{2}+\mathrm{hv} \rightarrow 2 \mathrm{HO}^{\bullet} \\
& \mathrm{H}_{2} \mathrm{O}+\mathrm{h} v \rightarrow \mathrm{H}^{\bullet}+\mathrm{HO}^{\bullet} \\
& \mathrm{R}-\mathrm{H}+\mathrm{HO}^{\bullet} \rightarrow \text { Produtos finais (p.ex. } \mathrm{CO}_{2}, \mathrm{H}_{2} \mathrm{O}, \mathrm{NO}_{3}^{-}, \mathrm{Cl}^{-} \text {) }
\end{aligned}
$$

O radical hidroxila pode reagir através de três mecanismos distintos: abstração de hidrogênio, transferência de elétrons e adição radicalar. Os radicais secundários formados durante estas reações podem novamente reagir com outros compostos. ${ }^{9}$ A Figura $1 \mathrm{~S}$ (Material Suplementar) ilustra algumas classes de compostos que podem ser decompostas pela ação da radiação UV e seus produtos de decomposição finais formados em solução. ${ }^{8}$

Vários procedimentos têm sido descritos na literatura para a decomposição de amostras de águas empregando radiação UV, os quais se baseiam na ação de uma fonte ininterrupta de calor em associação ao poder oxidante de um componente que age diretamente na amostra. A decomposição pode ser conduzida de maneira contínua ou em batelada, onde a amostra é geralmente colocada em um ou vários tubos de quartzo tampado(s), disposto(s) ao redor da fonte de radiação UV. ${ }^{5-8}$ Atualmente, existem alguns modelos de digestores UV comercialmente disponíveis, que contêm geralmente uma lâmpada de mercúrio de alta pressão (de 125 a $1000 \mathrm{~W}$ ) ${ }^{9}$ circundada por tubos de quartzo e um sistema de resfriamento por circulação forçada de ar 
e/ou de água para evitar a evaporação da amostra durante o processo. ${ }^{4}$ Nos últimos anos, versões simplificadas de digestores UV vêm sendo desenvolvidas em laboratórios de pesquisa, com o objetivo de minimizar os custos de aquisição e principalmente de manutenção do equipamento. Um exemplo é o digestor UV desenvolvido por Campos e colaboradores, ${ }^{4}$ que permite a irradiação simultânea de 5 amostras, as quais são mantidas a $70{ }^{\circ} \mathrm{C}$ durante o processo de mineralização sob circulação de ar. O sistema é provido de uma lâmpada de mercúrio de alta pressão $(125 \mathrm{~W})$ utilizada em iluminação pública, cujo bulbo externo foi removido para total exposição das amostras à radiação UV. Outros sistemas de irradiação UV desenvolvidos em laboratório são descritos na literatura, ${ }^{4,7,10}$ os quais utilizam lâmpadas de mercúrio de baixa, média e alta pressão com potências variadas. Sistemas de irradiação UV desenvolvidos em laboratório e que empregam bulbos de lâmpadas de mercúrio de alta pressão, com potências superiores a $125 \mathrm{~W}$, não foram descritos na literatura até o presente momento. O superaquecimento da amostra e a necessidade de um sistema de resfriamento eficiente adaptado ao sistema de irradiação, a fim de evitar a perda da amostra por evaporação, justificam a ausência de sistemas desenvolvidos em laboratório empregando fontes de radiação UV de alta potência (400-1000 W).

Este trabalho relata a otimização de etapas de decomposição de amostras para a destruição da matéria orgânica dissolvida em amostras de águas e fluidos biológicos, utilizando um sistema de irradiação UV com uma fonte de radiação de alta potência $(400 \mathrm{~W})$. A eficiência do sistema na destruição da matéria orgânica em amostras de águas modelo, águas naturais e fluidos biológicos foi investigada a partir de ensaios de recuperação de espécies metálicas $(\mathrm{Zn}, \mathrm{Cd}, \mathrm{Pb}, \mathrm{Cu}$, $\mathrm{Al}$ e Fe), a fim de demonstrar sua aplicabilidade na determinação e na análise de especiação química de metais. As espécies metálicas foram determinadas por voltametria de redissolução anódica (ASV) e voltametria adsortiva de redissolução catódica (AdCSV), antes e depois de serem submetidas à etapa de irradiação UV. Espectros de absorção molecular no UV/VIS foram registrados e ilustram a eficiente mineralização das amostras submetidas a diferentes tempos de irradiação UV no sistema desenvolvido.

\section{PARTE EXPERIMENTAL}

\section{Instrumentação}

Todas as medidas voltamétricas foram realizadas no Polarógrafo 693 VA Processor (Metrohm) em combinação com um 694 VA Stand (Metrohm), empregando uma célula convencional de três eletrodos: o eletrodo de mercúrio de gota pendente (HMDE) como eletrodo de trabalho e os eletrodos de $\mathrm{Ag} / \mathrm{AgCl}\left(\mathrm{KCl} 3 \mathrm{~mol} \mathrm{~L}^{-1}\right)$ e de platina $(\mathrm{Pt})$ como eletrodos de referência e auxiliar, respectivamente.

Os espectros de absorção molecular no UV-VIS foram obtidos entre 250 e $750 \mathrm{~nm}$ em um espectrofotômetro com arranjo de diodos HP 8453 (Hewlett Packard), utilizando uma célula de quartzo de 10 mm de espessura do caminho óptico.

O sistema de irradiação UV construído e utilizado neste trabalho consiste dos seguintes componentes básicos: uma fonte de radiação UV de alta potência, um sistema de resfriamento por circulação forçada de ar e água, um termo-regulador comercial para controle de temperatura, um suporte para 12 tubos de quartzo e um bloco envoltório à base de alumínio. A Figura 1 ilustra a composição do sistema de irradiação UV construído em laboratório. Como fonte de radiação UV foi empregada uma lâmpada de mercúrio de alta pressão com potência nominal de 400 W (a), utilizada em iluminação pública (marca Silvania). O bulbo da lâmpada foi exposto pela remoção do invólucro externo. A lâmpada com o bulbo exposto foi afixada na parte inferior do sistema onde está posicionado o soquete da lâmpada (b). O sistema de resfriamento foi constituído de um cooler posicionado na parte inferior do sistema (c), o qual é acionado ou desligado automaticamente pelo sensor de temperatura do termo-regulador quando a temperatura excede ou diminui em $0,1^{\circ} \mathrm{Co}$ valor estabelecido no display do termo-regulador. O termo-regulador utilizado, da marca Tholz (modelo MDH), possui um sensor metálico de temperatura (j) mergulhado em um dos tubos contendo a amostra. Além da circulação de ar forçada, o sistema de resfriamento possui um canal de $0,8 \mathrm{~cm}$ de diâmetro (h) entre a parte externa e interna do cilindro de alumínio por onde circula água (a temperatura ambiente) de forma ininterrupta durante o processo de irradiação. A combinação dos sistemas de acionamento do cooler e de circulação constante de água consiste no sistema de resfriamento do sistema de irradiação. O suporte para 12 tubos de quartzo (e) foi construído e moldado em aço inoxidável, com dimensões precisas, de modo que os tubos permaneçam dentro do sistema circundando o bulbo da lâmpada UV. Os tubos de quartzo (d) utilizados foram obtidos comercialmente (Metrohm) e possuem dimensões de 12,5 $\mathrm{cm}$ de comprimento e $1,5 \mathrm{~cm}$ de diâmetro interno, com capacidade máxima para $10 \mathrm{~mL}$ de amostra. Em uma caixa metálica (B), estão colocados a fonte de alimentação geral do sistema com entrada de 110 e $220 \mathrm{~V}$, o reator de $400 \mathrm{~W}$ para a lâmpada de mercúrio, uma fonte estabilizada que alimenta o cooler através de um transformador de entrada 110-220 V e saída $24 \mathrm{~V}$, a chave liga/desliga da lâmpada UV e a chave geral do sistema.

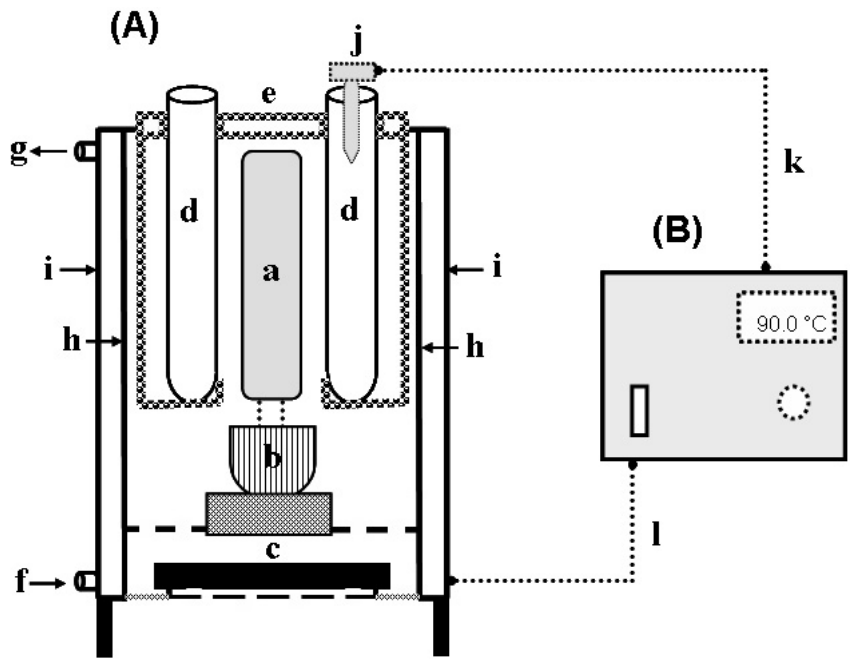

Figura 1. Representação esquemática do sistema de irradiação $U V$ desenvolvido: (A) a) lâmpada UV (mercúrio de alta pressão - $400 \mathrm{~W}$ ); b) soquete da lâmpada $U V$; c) cooler; d) tubos de quartzo; e) suporte para os tubos de quartzo; f) conexão de entrada de água; g) conexão de saída de água; h) canal de 0,8 cm de diâmetro interno para circulação de água; $i)$ bloco envoltório à base de alumínio; $j$ ) sensor metálico de temperatura; (B) k) cabo de conexão do sensor de temperatura; l) cabo de conexão do sistema de irradiação com a fonte

\section{Reagentes e soluções}

Todas as soluções foram preparadas com água ultrapura destilada e deionizada em sistema Milli Q (Millipore) e todos os reagentes utilizados foram de grau analítico. Soluções padrão $1 \mathrm{~g} \mathrm{~L}^{-1} \mathrm{dos}$ metais $\mathrm{Zn}$ (II), $\mathrm{Cd}(\mathrm{II}), \mathrm{Pb}(\mathrm{II}), \mathrm{Cu}(\mathrm{II}), \mathrm{Al}(\mathrm{III})$ e $\mathrm{Fe}$ (III) foram obtidos da Specsol (NIST, USA). Peróxido de hidrogênio $\left(\mathrm{H}_{2} \mathrm{O}_{2}\right) 30 \%$ (v/v), ácido acético glacial $\left(\mathrm{CH}_{3} \mathrm{COOH}\right)$, ácido sulfúrico $\left(\mathrm{H}_{2} \mathrm{SO}_{4}\right) 98 \%$ (w/w), hidróxido de amônio $\left(\mathrm{NH}_{4} \mathrm{OH}\right) 25 \%(\mathrm{w} / \mathrm{w})$, dicromato de potássio $\left(\mathrm{K}_{2} \mathrm{Cr}_{2} \mathrm{O}_{7}\right)$, sulfato ferro amoniacal $\left[\left(\mathrm{NH}_{4}\right)_{2} \mathrm{Fe}\left(\mathrm{SO}_{4}\right)_{2} \cdot 6 \mathrm{H}_{2} \mathrm{O}\right]$ e difenilamina foram obtidos da Merck (Darmstadt, Germany). 
A solução de tampão acetato em pH 4,6 $\left(\mathrm{CH}_{3} \mathrm{COOH} 2 \mathrm{~mol} \mathrm{~L}^{-1} /\right.$ $\mathrm{NH}_{4} \mathrm{OH} 1 \mathrm{~mol} \mathrm{~L}^{-1}$ ) foi preparada pela mistura de $55,5 \mathrm{~mL}$ de ácido acético glacial e $37 \mathrm{~mL}$ de hidróxido de amônio $25 \%$ em $500 \mathrm{~mL}$ de água. A solução estoque do agente complexante violeta de solocromo RS (SVRS) na concentração $0,01 \mathrm{~mol} \mathrm{~L}^{-1}$ foi preparada pela dissolução apropriada do reagente (ACROS, New Jersey, USA) em água.

A solução de trabalho contendo os metais $\mathrm{Zn}$ (II) $10 \mathrm{mg} \mathrm{L}^{-1}, \mathrm{Cd}$ (II) $0,5 \mathrm{mg} \mathrm{L}^{-1}, \mathrm{~Pb}$ (II) $0,5 \mathrm{mg} \mathrm{L}^{-1}$ e Cu(II) $2,5 \mathrm{mg} \mathrm{L}^{-1}$ foi obtida pela diluição apropriada da solução padrão $1 \mathrm{~g} \mathrm{~L}^{-1}$. A solução de trabalho do complexo Al-SVRS $2 \mathrm{mg} \mathrm{L}^{-1}$ foi preparada pela mistura de $3,5 \mathrm{~mL}$ de água ultrapura, $2 \mathrm{~mL}$ de uma solução de $\mathrm{Al} 10 \mathrm{mg} \mathrm{L}^{-1}, 0,5 \mathrm{~mL}$ de tampão acetato $\mathrm{pH}$ 4,6 e $4 \mathrm{~mL}$ de SVRS 0,01 $\mathrm{mol} \mathrm{L}^{-1}$. Esta solução foi aquecida a $90{ }^{\circ} \mathrm{C}$ por 10 min para a formação do complexo, o qual era preparado diariamente. A solução de trabalho do complexo Fe-SVRS $2 \mathrm{mg} \mathrm{L}^{-1}$ foi preparada da mesma forma, porém sem a etapa de aquecimento, devido ao fato de a velocidade de formação do complexo Fe-SVRS ser rápida. ${ }^{2,11}$

\section{Amostras}

A amostra de água modelo contendo o tensoativo Triton X-100, EDTA e ácido pícrico na concentração $10 \mathrm{mg} \mathrm{L}^{-1}$ (cada) foi preparada pela dissolução dos reagentes em água. Esta amostra possui um conteúdo de carbono orgânico total de $10,8 \mathrm{mg} \mathrm{L}^{-1}$ e representa uma amostra de água altamente contaminada com uma espécie tensoativa (Triton X-100), um agente complexante (EDTA) e uma espécie eletroquimicamente ativa no eletrodo de mercúrio (ácido pícrico), simulando assim 3 tipos de interferências possíveis na determinação voltamétrica de metais. ${ }^{1,8} \mathrm{~A}$ amostra de água modelo contendo ácido húmico na concentração $100 \mathrm{mg} \mathrm{L}^{-1}$ foi preparada pela dissolução do reagente em água. Esta amostra representa uma amostra de água altamente contaminada com um agente complexante natural para metais, o que os torna indisponíveis para a reação de transferência de elétrons no eletrodo de mercúrio. , $7,10^{-}$

As amostras de águas naturais utilizadas foram água do mar (superficial), coletada na praia de Xangri-lá (RS) e água de córrego, coletada no campus da Universidade Federal de Santa Maria (RS).

As amostras de fluidos biológicos utilizadas neste trabalho foram urina humana, coletada pelo próprio analista no dia de análise e fluidos pós-hemodiálise, coletados no setor de nefrologia do Hospital Universitário de Santa Maria (RS) de pacientes em tratamento dialítico. As amostras de urina foram coletadas diariamente pelo próprio analista, armazenadas sob refrigeração $\left(4^{\circ} \mathrm{C}\right)$ e utilizadas ao longo de 1 dia de trabalho. As amostras de fluidos pós-hemodiálise foram armazenadas sob refrigeração $\left(4^{\circ} \mathrm{C}\right)$ e utilizadas por um período máximo de 1 mês.

\section{Procedimentos analíticos}

Determinação simultânea de $\mathrm{Zn}(\mathrm{II}), \mathrm{Cd}(\mathrm{II}), \mathrm{Pb}(\mathrm{II})$ e $\mathrm{Cu}(\mathrm{II})$ e de $\mathrm{Al}(\mathrm{III})$ e $\mathrm{Fe}(\mathrm{III})$

As determinações de $\mathrm{Zn}$ (II), $\mathrm{Cd}$ (II), $\mathrm{Pb}$ (II) e $\mathrm{Cu}$ (II) foram realizadas por voltametria de redissolução anódica (ASV). O método baseia-se na deposição dos metais por um período de 60 s no eletrodo de mercúrio de gota pendente (HMDE) em um potencial de $-1,15 \mathrm{~V}$ e na oxidação destes durante a varredura anódica dos potencias $\left(60 \mathrm{mV} \mathrm{s}^{-1}\right)$ entre $-1,15$ e $+0,15 \mathrm{~V} \cdot{ }^{1,12} \mathrm{O}$ eletrólito suporte utilizado nas medidas foi o tampão acetato $\mathrm{pH} 4,6$. Após o desaeramento das soluções por 5 min, as concentrações dos metais foram determinadas pelo método da adição do padrão $(n=3)$ com a adição de $100 \mu \mathrm{L}$ da solução de trabalho dos metais $\mathrm{Zn}$ (II) $10 \mathrm{mg} \mathrm{L}^{-1}$, Cd(II) 0,5 mg L-1, Pb(II) 0,5 $\mathrm{mg} \mathrm{L}^{-1} \mathrm{e} \mathrm{Cu}$ (II) $2,5 \mathrm{mg} \mathrm{L}^{-1}$. Os limites de quantificação $(10 \sigma / \mathrm{b})$ calculados para os metais são: $1,50 \mu \mathrm{g} \mathrm{L}^{-1}$ para $\mathrm{Zn}(\mathrm{II}) ; 2,00 \mu \mathrm{g} \mathrm{L}{ }^{-1}$ para $\mathrm{Cu}(\mathrm{II}) ; 0,10 \mu \mathrm{g}$
$\mathrm{L}^{-1}$ para $\mathrm{Cd}(\mathrm{II})$ e $0,10 \mu \mathrm{g} \mathrm{L} \mathrm{L}^{-1}$ para $\mathrm{Pb}(\mathrm{II})$.

As determinações de $\mathrm{Al}(\mathrm{III})$ e $\mathrm{Fe}$ (III) foram realizadas por voltametria adsortiva de redissolução catódica (AdCSV). O método baseia-se na deposição adsortiva dos complexos Al-SVRS e Fe-SVRS por um período de $5 \mathrm{~s}$ no eletrodo de mercúrio de gota pendente (HMDE) em um potencial de $-0,1 \mathrm{~V}$ e na redução destes durante a varredura catódica dos potenciais $\left(20 \mathrm{mV} \mathrm{s}^{-1}\right)$ entre $-0,1 \mathrm{e}-0,8 \mathrm{~V}{ }^{2}$ $\mathrm{O}$ eletrólito suporte utilizado foi o tampão acetato $\mathrm{pH} 4,6$. Devido à baixa velocidade de formação do complexo de $\mathrm{Al}$ com SVRS, as soluções de medidas foram aquecidas a $90{ }^{\circ} \mathrm{C}$ por $10 \mathrm{~min}$ em um banho termostatizado antes de cada determinação. As determinações voltamétricas foram realizadas com as soluções à temperatura ambiente, precedidas do desaeramento das soluções por 5 min. As concentrações dos metais foram determinadas pelo método da adição do padrão $(n=3)$ com a adição de $100 \mu \mathrm{L}$ da solução de trabalho dos complexos Al-SVRS $2 \mathrm{mg} \mathrm{L}^{-1}$ e Fe-SVRS $2 \mathrm{mg} \mathrm{L}^{-1}$. Os limites de quantificação $(10 \sigma / b)$ calculados para os metais são: $1,40 \mu \mathrm{g} \mathrm{L}^{-1}$ para $\mathrm{Al}(\mathrm{III})$ e $1,90 \mu \mathrm{g} \mathrm{L}^{-1}$ para $\mathrm{Fe}(\mathrm{III})$.

\section{Decomposição das amostras empregando radiação $U V e$ determinação voltamétrica dos metais}

O fluxograma apresentado na Figura 2S (Material Suplementar) descreve o procedimento adotado para o estudo da decomposição das amostras de águas, fluidos pós-hemodiálise e urina empregando radiação UV. No estudo da eficiência de decomposição das amostras estudadas, ensaios de recuperação foram realizados com cada metal na concentração de $25 \mu \mathrm{g} \mathrm{L} \mathrm{L}^{-1}$. Após a etapa de decomposição empregando radiação UV, os metais eram determinados $(n=3)$ por ASV e AdCSV, como descrito anteriormente.

\section{Determinação do carbono orgânico total}

A determinação do carbono orgânico total nas amostras estudadas foi realizada pelo método titulométrico com $\mathrm{K}_{2} \mathrm{Cr}_{2} \mathrm{O}_{7}$, como descrito previamente na literatura. ${ }^{13} \mathrm{O}$ método baseia-se na oxidação, por via úmida, do carbono orgânico contido nas amostras com $\mathrm{K}_{2} \mathrm{Cr}_{2} \mathrm{O}_{7}$ em excesso e ácido sulfúrico concentrado, promovendo-se o aquecimento externo. Segue-se a determinação do $\mathrm{K}_{2} \mathrm{Cr}_{2} \mathrm{O}_{7}$ remanescente por titulação com solução de $\left(\mathrm{NH}_{4}\right)_{2} \mathrm{Fe}\left(\mathrm{SO}_{4}\right)_{2} \cdot 6 \mathrm{H}_{2} \mathrm{O}$ padronizada.

\section{RESULTADOS E DISCUSSÃO}

\section{Estudo da influência da radiação UV sobre a mineralização das amostras na presença de $\mathrm{H}_{2} \mathrm{O}_{2}$}

Primeiramente ensaios envolvendo fotólise direta, ou seja, sem adição de $\mathrm{H}_{2} \mathrm{O}_{2}$ como precursor radicalar, foram realizados para verificação de uma possível fotodegradação da amostra sem a influência de fatores extrínsecos ao sistema. Para estes ensaios não foi observada voltametricamente uma mineralização (fotodegradação) da amostra após 4 h de fotólise direta, evidenciando assim a fotoestabilidade da amostra. Uma vez comparado o espectro da lâmpada de mercúrio de alta pressão $0^{9}$ com os espectros das amostras, percebe-se que as bandas de absorção da amostra não são coincidentes com as raias majoritárias de emissão da lâmpada de $\mathrm{Hg}$ de alta pressão, que apresenta uma emissão policromática. ${ }^{9}$ Este fator explica a fotoestabilidade da amostra quando submetida apenas à fotólise direta.

A adição de $\mathrm{H}_{2} \mathrm{O}_{2}$ aumenta a eficiência de mineralização de amostras por radiação UV, devido à formação de radicais $\mathrm{HO}^{\bullet} \mathrm{em}$ maior concentração e sua subseqüente reação de degradação com a matéria orgânica (reação 3). Além disso, a degradação indireta de substâncias orgânicas por um mecanismo radicalar é bastante acelerada se o processo é realizado a $90{ }^{\circ} \mathrm{C}$. Apenas nesta temperatura forma-se uma concentração suficientemente alta de radicais $\mathrm{HO}^{*}$ no 
A

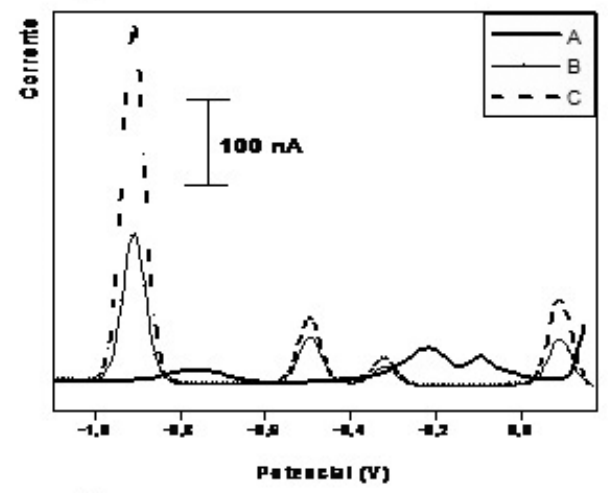

$B$

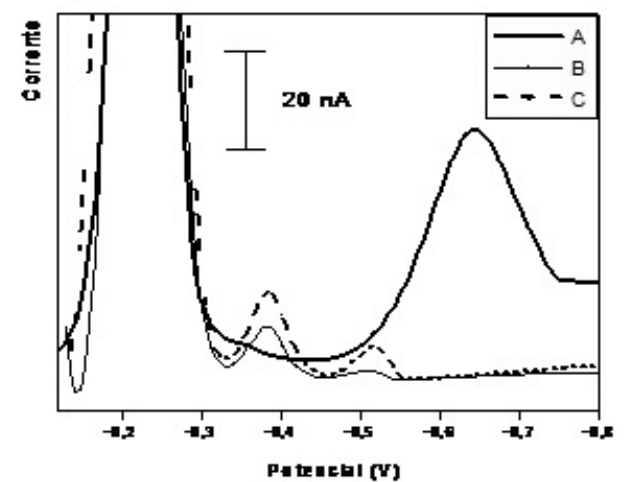

Figura 2. Voltamogramas de redissolução das amostras de urina contaminadas com (A) $25 \mu g L^{-1}$ de $\mathrm{Zn}(I I), C d(I I), P b(I I), C u(I I)$ e (B) $25 \mu g L^{-1}$ de Al(III) e Fe(III). Voltamogramas A: amostras não-irradiadas; Voltamogramas B: amostras após $4 \mathrm{~h}$ de irradiação; Voltamogramas $C$ : amostras após $4 \mathrm{~h}$ de irradiação + adição de $100 \mu \mathrm{g} L^{-1}$ de $\mathrm{Zn}, 5 \mu \mathrm{g} L^{-1}$ de Cd, $5 \mu \mathrm{g} L^{-1}$ de $\mathrm{Pb}, 25$ $\mu \mathrm{g} L^{-1}$ de Cu, $20 \mu g L^{-1}$ de Al e $20 \mu g L^{-1}$ de Fe. Condições de irradiação como descrito na Figura $2 S$ (Material suplementar)

meio reacional. Aliado a isso, a acidificação de amostras contendo $\mathrm{H}_{2} \mathrm{O}_{2}$ também melhora a eficiência de mineralização, uma vez que provoca a dissociação dos complexos orgânicos lábeis formados com metais..$^{1,7,9,12}$ Assim, a fim de aumentar e acelerar a mineralização das amostras, utilizou-se $\mathrm{H}_{2} \mathrm{O}_{2}$ em conjunto com $\mathrm{H}_{2} \mathrm{SO}_{4}$ para todas as amostras no início do processo de irradiação. É sabido que oxidações com $\mathrm{H}_{2} \mathrm{O}_{2}$ em misturas ácidas contendo $\mathrm{H}_{2} \mathrm{SO}_{4}$ são baseadas, também, na produção in situ de ácido permonossulfúrico. ${ }^{14}$

Após o estabelecimento das condições de irradiação UV (adição de $\mathrm{H}_{2} \mathrm{O}_{2}$ e $\mathrm{H}_{2} \mathrm{SO}_{4}$ ), o perfil dos espectros de absorção UV/Vis das amostras foi empregado no estudo da influência da radiação UV, produzida no sistema de irradiação construído em laboratório (Figura 1), sobre as amostras estudadas. A Figura $3 \mathrm{~S}$ mostra os espectros de absorção UV/Vis das amostras de água modelo, ácido húmico 100 mg L ${ }^{-1}$, fluido pós-hemodiálise e urina, registrados antes e após a etapa de irradiação UV (2 e 4 h).

A Figura 3S (Material Suplementar) mostra os espectros de absorção UV/Vis da solução de ácido húmico $100 \mathrm{mg} \mathrm{L}^{-1}$, onde se observa para a amostra não irradiada uma forte absorção na região UV, devido à presença das substâncias húmicas dissolvidas. Após a etapa de irradiação UV por 2 e 4 h, observa-se o desaparecimento da cor da amostra e o decréscimo significativo das bandas de absorção na região UV e Vis devido à completa mineralização da solução. Como descrito anteriormente, uma lâmpada de $\mathrm{Hg}$ de alta pressão foi utilizada como fonte de radiação, a qual emite um espectro de raias policromático com uma intensidade máxima relativa em 254 $\mathrm{nm}$. Por se tratar de uma emissão policromática, outros comprimentos de onda podem vir a colaborar minoritariamente na fotodegradação do ácido húmico. Conhecendo-se o espectro da lâmpada utilizada e o espectro da amostra a ser mineralizada, torna-se possível predizer, teoricamente, o quanto a fotodegradação direta será eficiente, uma vez que a absorção da amostra deve ser condizente ou se interpor, $a$ priori, com o espectro de emissão da lâmpada. ${ }^{9}$ Na Figura $3 \mathrm{~S}-\mathrm{B}$, o espectro UV/Vis da água modelo contendo ácido pícrico, EDTA e Triton X-100 apresenta uma forte absorção na região entre 300 e 450 $\mathrm{nm}$, devido à presença de ácido pícrico na sua composição. Entretanto, após a irradiação UV da amostra por 2 e 4 h observa-se o completo desaparecimento de sua cor (amarela) e das bandas de absorção no UV/Vis típicas da amostra modelo. O mesmo comportamento foi observado para as amostras de água do mar e água do córrego, onde o completo desaparecimento de pequenas bandas de absorção no $\mathrm{UV}$, devido à menor concentração de matéria orgânica em relação às amostras anteriores, foi observado após 2 e 4 h de irradiação UV. A amostra de fluido pós-hemodiálise, apesar de ser proveniente de uma matriz complexa com diferentes compostos orgânicos, apresenta um espectro de absorção bem definido na região UV (Figura 3S-C). Nele, observa-se uma diminuição significativa da absorção entre 200 e $300 \mathrm{~nm}$ após 2 e 4 h de irradiação UV. Já para a amostra de urina, o espectro de absorção UV/Vis, Figura 3S-D, ilustra a complexidade da matriz. Nestes espectros, observa-se que a absorção da urina na região entre 350 e $500 \mathrm{~nm}$ após $2 \mathrm{~h}$ de irradiação UV é maior que a da amostra não-irradiada. Isto ocorre, muito provavelmente, pela incompleta mineralização da amostra após $2 \mathrm{~h}$ de irradiação, o que pode ser comprovado pelo não desaparecimento da cor e pela presença de substâncias em suspensão na amostra irradiada. Entretanto, a irradiação UV da amostra de urina por $4 \mathrm{~h}$ promove a completa eliminação da cor da amostra e das substâncias em suspensão, o que pode ser comprovado também pelo decréscimo significativo da absorção no UV/Vis (Figura 3S-D). Entretanto, a completa mineralização da amostra de urina só é possível com a adição repetida de $\mathrm{H}_{2} \mathrm{O}_{2} 30 \%$ $(50 \mu \mathrm{L})$ a cada hora de irradiação.

O perfil dos espectros de absorção UV/Vis das amostras submetidas à irradiação UV mostra que o sistema de irradiação construído com uma lâmpada de mercúrio comercial $(400 \mathrm{~W})$ possibilita a mineralização eficiente das amostras de águas e biológicas após 2 h. Entretanto, uma avaliação quantitativa da eficiência da mineralização das amostras em relação ao tempo de irradiação UV se faz necessária. No próximo item, ensaios de recuperação para os metais $\mathrm{Zn}, \mathrm{Cd}$, $\mathrm{Pb}, \mathrm{Cu}, \mathrm{Al}$ e $\mathrm{Fe}$ em amostras fortificadas e submetidas a diferentes tempos de irradiação UV demonstram a cinética de decomposição da matéria orgânica e a eficiência da mineralização das amostras para a análise voltamétrica.

\section{Estudo da eficiência de mineralização das amostras com radiação $\mathrm{UV}$}

A eficiência do sistema de irradiação desenvolvido em laboratório na destruição da matéria orgânica dissolvida presente nas amostras foi testada a partir de ensaios de recuperação, os quais foram realizados em $10 \mathrm{~mL}$ de amostra fortificada com cada metal estudado na concentração de $25 \mu \mathrm{g} \mathrm{L}^{-1}$. Essas amostras foram submetidas a diferentes tempos de irradiação (2, 4 e 6 h), após o qual a concentração de cada metal era determinada pelo método da adição do padrão $(n=3)$.

A Figura 2 ilustra os voltamogramas de uma amostra de urina antes e após a etapa de irradiação UV por $4 \mathrm{~h}$. Como pode ser observado, a determinação dos metais $\mathrm{Zn}, \mathrm{Cd}, \mathrm{Pb}$ e $\mathrm{Cu}$ por ASV e dos metais Al e Fe por AdCSV só é possível após a irradiação das amostras por no mínimo $4 \mathrm{~h}$ (voltamogramas B) no sistema de irradiação desenvolvido, o que está de acordo com os resultados demonstrados nos espectros de absorção UV/Vis (Figura 3S). A interferência da 
A
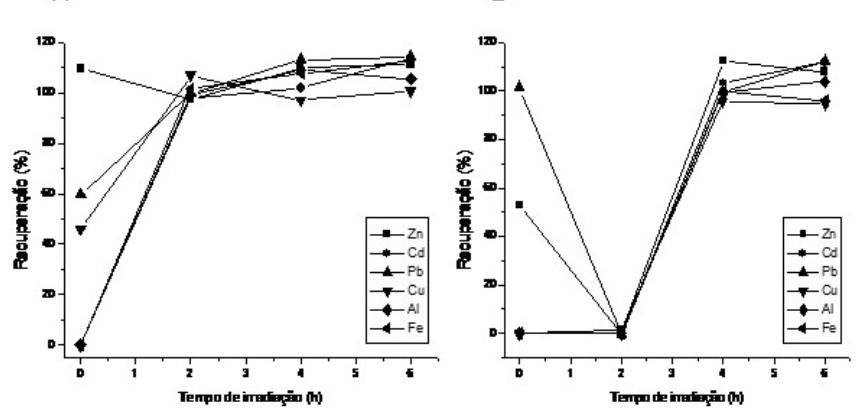

Figura 3. Estudo da eficiência de mineralização das amostras de (A) ácido húmico $100 \mathrm{mg} \mathrm{L}^{-1} e(B)$ urina humana a partir de ensaios de recuperação dos metais $\left(25 \mu \mathrm{g} L^{-1}\right)$ adicionados às amostras. As determinações dos metais por ASV foram realizadas pelo método da adição do padrão $(\mathrm{n}=3)$. Condições de irradiação: como descrito na Figura $2 S$ (Material suplementar)

matéria orgânica dissolvida na determinação voltamétrica dos metais nas amostras não-irradiadas pode ser observada pela ausência de sinais voltamétricos nas amostras fortificadas com $25 \mu \mathrm{g} \mathrm{L}^{-1}$ de cada metal (voltamogramas A).

A eficiência da irradiação UV na mineralização das amostras fortificadas com cada metal pode ser vista nas Figuras 3 e 4 S (Material Suplementar). Como mostra a Figura 3A, uma recuperação satisfatória para o elemento adicionado à amostra de ácido húmico $100 \mathrm{mg} \mathrm{L}^{-1}$ não-irradiada foi obtida apenas para zinco (109,8\%), demonstrando que a determinação deste metal por ASV não sofre uma influência significativa do ácido húmico presente na amostra. Para os metais chumbo e cobre, recuperações de 59,8 e 46,2\%, respectivamente, mostram que estes elementos se encontram parcialmente complexados pelo ácido húmico, o que os torna menos disponíveis para a medida voltamétrica. Já a determinação voltamétrica de cádmio, alumínio e ferro não foi possível na amostra não-irradiada, devido à interferência do ácido húmico causada pela forte complexação deste com os metais em solução. Após 2 h de irradiação UV da solução de ácido húmico $100 \mathrm{mg} \mathrm{L}^{-1}$, recuperações para todos os metais em torno de $100 \%$ evidenciam a eficiente mineralização da amostra no sistema de irradiação desenvolvido.

A urina humana, por ser uma matriz biológica complexa, torna difícil a determinação de traços metálicos sem uma etapa de prétratamento da amostra. Primeiramente, abservou-se que a determinação voltamétrica direta da amostra de urina levou à formação de uma grande quantidade de espuma na célula voltamétrica durante o borbulhamento de $\mathrm{N}_{2}$ nas soluções. Segundo Golimowski, ${ }^{9}$ a formação de espuma é um indício da presença de compostos orgânicos dissolvidos na amostra. Na Figura 3B, observa-se que, sem a etapa de irradiação UV, apenas a determinação de chumbo se torna teoricamente possível na amostra de urina (recuperações de 101,5\%), o que também já foi demonstrado nos voltamogramas da Figura 2. Entretanto, a determinação dos metais não é possível mesmo após 2, 4 e $6 \mathrm{~h}$ de irradiação da amostra, devido à presença significativa de material em suspensão e cor na amostra de urina. Para contornar este problema, optou-se em aumentar a concentração de radicais $\mathrm{HO}^{*}$ pela adição repetida de $\mathrm{H}_{2} \mathrm{O}_{2}$ durante o processo de irradiação (50 $\mu \mathrm{L}$ de $\mathrm{H}_{2} \mathrm{O}_{2} 30 \%$ a cada hora). Ainda assim, o tempo de irradiação de $2 \mathrm{~h}$ não foi suficiente para eliminar a cor e o material em suspensão na amostra de urina, o que pode ser observado pelos valores de recuperação insignificantes para os metais na Figura 3B. Apenas após 4 e 6 h de irradiação UV, com adições repetidas de $\mathrm{H}_{2} \mathrm{O}_{2}$, a amostra de urina foi completamente mineralizada, com valores de recuperação para todos os metais em torno de $100 \%$ (Figura 3B). Portanto, a mineralização completa da amostra de urina envolve a irradiação UV durante $4 \mathrm{~h}$ com adição de $\mathrm{H}_{2} \mathrm{O}_{2} 30 \%(50 \mu \mathrm{L})$ no início e a cada hora de irradiação.

A Figura 4S-A (Material Suplementar) mostra um comportamento semelhante ao da solução de ácido húmico $100 \mathrm{mg} \mathrm{L}^{-1}$ para a amostra de água modelo fortificada com os metais. Entretanto, a forte interferência da amostra contendo EDTA (um agente complexante), ácido pícrico (um composto orgânico eletroquimicamente ativo) e Triton X-100 (um tensoativo não-iônico) impede a determinação voltamétrica de todos os metais estudados. Após a determinação dos metais nas amostras mineralizadas por 2, 4 e $6 \mathrm{~h}$, verificou-se que 2 $\mathrm{h}$ de irradiação UV foram suficientes para eliminar a interferência da matriz, com recuperações em torno de $100 \%$ para todos os elementos adicionados. Já para o zinco, tempos de irradiação maiores que $2 \mathrm{~h}$ levam a um aumento na recuperação, com 188,6\% de recuperação após $6 \mathrm{~h}$ de irradiação. Este fato deve-se, possivelmente, à interferência dos sub-produtos formados durante a etapa de irradiação UV que interagem com o metal e interferem na medida voltamétrica.

As Figuras 4S-B e 4S-C (Material Suplementar) mostram a dependência da eficiência de mineralização de duas amostras reais de água em relação ao tempo de irradiação UV. Novamente se observa o mesmo comportamento obtido em soluções modelo, onde a determinação da concentração total de alguns metais não é possível em amostras não-irradiadas. Após a etapa de irradiação UV por períodos de tempo entre 2 e 4 h, observou-se que os valores de recuperação se mantiveram em torno de $100 \%$ para todos os elementos estudados. Portanto, o tempo de $2 \mathrm{~h}$ de irradiação UV mostrou ser suficiente para eliminar os interferentes da matriz tanto na água de córrego (Figura 4S-B) como na água do mar (Figura 4S-C). Para tempos de irradiação UV maiores que $4 \mathrm{~h}$, ocorrem oscilações maiores nos percentuais de recuperação, devido provavelmente à formação de sub-produtos que interagem com os metais e interferem na medida voltamétrica dos metais por ASV e AdCSV.

Os fluidos pós-hemodiálise representam uma matriz complexa composta por diferentes substâncias dissolvidas, como sais, espécies orgânicas e inorgânicas dialisadas durante as sessões de hemodiálise. $\mathrm{Na}$ Figura 4S-D, observa-se que as porcentagens de recuperação foram inferiores a $86 \%$ na determinação direta dos metais no fluido (sem a etapa de irradiação UV), comprovando a necessidade de eliminação dos compostos orgânicos presentes nessa matriz. Após a determinação dos metais no fluido pós-hemodiálise mineralizado após 2, 4 e 6 h, verificou-se que a aplicação de 2 h de radiação UV foi suficiente para destruir a matéria orgânica interferente, com recuperações em torno de $100 \%$ para os metais $\left(25 \mu \mathrm{g} \mathrm{L}^{-1}\right)$ adicionados às amostras. Para os tempos de 4 e 6 h de irradiação UV, observa-se uma grande oscilação nas porcentagens de recuperação, comprovando a formação de subprodutos interferentes na ASV e AdCSV durante a etapa de radiação UV.

Para confirmar a eficiência de decomposição das amostras após irradiação UV na presença de $\mathrm{H}_{2} \mathrm{O}_{2}$, a redução no carbono orgânico total foi também determinada após o tratamento das amostras com maior teor de matéria orgânica dissolvida. Os valores obtidos para as amostras irradiadas por $2 \mathrm{~h}$ (ácido húmico $100 \mathrm{mg} \mathrm{L}^{-1}$, água modelo e fluido pós-hemodiálise) e $4 \mathrm{~h}$ (urina) na presença de $\mathrm{H}_{2} \mathrm{O}_{2}$ foram os seguintes: $83,4 \%$ de redução para a solução de ácido húmico $100 \mathrm{mg} \mathrm{L}^{-1}$, $88,4 \%$ de redução para a amostra de água modelo (Triton X-100, EDTA e ácido pícrico na concentração de $10 \mathrm{mg} \mathrm{L}^{-1}$ cada), $86,7 \%$ de redução para a amostra de fluido pós-hemodiálise e $92,0 \%$ de redução para a amostra de urina. Uma taxa média de redução do carbono orgânico total de $87,6 \pm 3,1 \%$ foi obtida para todas as amostras estudadas.

A Tabela 1 apresenta os resultados dos ensaios de recuperação para os metais $\mathrm{Zn}, \mathrm{Cd}, \mathrm{Pb}, \mathrm{Cu}, \mathrm{Al}$ e Fe realizado em amostras fortificadas com cada metal nas concentrações de 10 e $20 \mu \mathrm{g} \mathrm{L}^{-1}$ e submetidas à irradiação UV nas condições otimizadas. 
Tabela 1. Ensaios de recuperação para $\mathrm{Zn}(\mathrm{II}), \mathrm{Cd}(\mathrm{II}), \mathrm{Pb}(\mathrm{II}), \mathrm{Cu}(\mathrm{II})$, $\mathrm{Al}(\mathrm{III})$ e Fe(III) em amostras fortificadas submetidas à irradiação UV (tempo de irradiação: $2 \mathrm{~h}$; condições experimentais: $50 \mu \mathrm{L}$ de $\mathrm{H}_{2} \mathrm{O}_{2}$ $30 \%, 10 \mu \mathrm{L}$ de $\mathrm{H}_{2} \mathrm{SO}_{4}, \mathrm{~T}=90{ }^{\circ} \mathrm{C}$ )

\begin{tabular}{|c|c|c|c|c|c|c|c|}
\hline \multirow[b]{2}{*}{ Amostra } & \multicolumn{7}{|c|}{ Metal recuperado $(\%)^{a}$} \\
\hline & $\begin{array}{c}\text { Metal } \\
\text { adicionad } \\
\left(\mu \mathrm{g} \mathrm{L}^{-1}\right)\end{array}$ & $\mathrm{Zn}$ & $\mathrm{Cd}$ & $\mathrm{Pb}$ & $\mathrm{Cu}$ & $\mathrm{Al}$ & $\mathrm{Fe}$ \\
\hline Água & 10 & 99,40 & 103,30 & 98,00 & 100,20 & 100,70 & 99,9 \\
\hline modelo $^{b}$ & 20 & 98,80 & 101,15 & 96,15 & 101,70 & 104,30 & 102, \\
\hline Ácido $\mathrm{h}$ & mico 10 & 100,09 & 102,80 & 96,30 & 98,80 & 98,40 & 97,9 \\
\hline $100 \mathrm{mg} \mathrm{L}^{-}$ & $-1 \quad 20$ & 99,95 & 99,35 & 99,30 & 98,15 & 98,35 & 98,9 \\
\hline Água d & nar 10 & $\begin{array}{c}102,80 \\
99,35\end{array}$ & $\begin{array}{l}105,10 \\
101,60\end{array}$ & $\begin{array}{c}99,80 \\
100,35\end{array}$ & $\begin{array}{c}104,60 \\
97,65\end{array}$ & $\begin{array}{c}101,80 \\
97,55\end{array}$ & \\
\hline
\end{tabular}

$\begin{array}{llllllll}\text { Água de } \quad 10 & 100,90 & 98,10 & 99,20 & 97,80 & 100,30 & 98,30\end{array}$

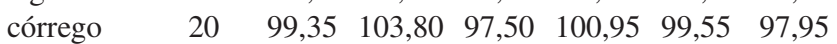
(UFSM)

Fluido pós- $10 \quad 100,40 \quad 116,00 \quad 104,10 \quad 98,90 \quad 101,30 \quad 102,90$ hemodiálise $20 \quad 97,90 \quad 98,95 \quad 100,60 \quad 100,40 \quad 99,45 \quad 97,40$

$\begin{array}{llllllll}\text { Urina } & 10 & 98,20 & 97,50 & 95,50 & 101,50 & 100,50 & 98,80\end{array}$

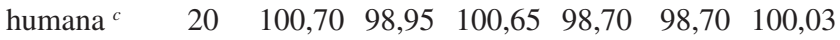

${ }^{a} \operatorname{RSD}(n=3): 0,5-3 \% ;{ }^{b}$ Triton X-100, EDTA e ácido pícrico na concentração de $10 \mathrm{mg} \mathrm{L}^{-1}$ (cada); ${ }^{c}$ tempo de irradiação: $4 \mathrm{~h}$; condições experimentais: 4 adições de $50 \mu \mathrm{L}$ de $\mathrm{H}_{2} \mathrm{O}_{2} 30 \%$ (no início e a cada hora), $10 \mu \mathrm{L}$ de $\mathrm{H}_{2} \mathrm{SO}_{4}, \mathrm{~T}=90{ }^{\circ} \mathrm{C}$

\section{Análise de especiação de metais por ASV e AdCSV associada à irradiação UV das amostras}

O uso da irradiação UV associada às técnicas voltamétricas consiste em uma importante ferramenta em procedimentos de especiação química, pois permite a discriminação entre a fração livre e a fração combinada de metais em diferentes tipos de amostras. A determinação da fração livre é baseada na determinação voltamétrica direta do elemento eletroquimicamente ativo (lábil), o qual se apresenta na forma livre $\left(\mathrm{M}^{\mathrm{n}+}\right)$ ou fracamente complexado. A determinação da fração combinada do metal, o qual se apresenta fortemente ligado aos componentes orgânicos da amostra, é baseada na diferença entre a concentração total do elemento (determinado após a mineralização completa da amostra) e a fração livre. A Tabela 2 apresenta os resultados da análise de especiação química dos elementos em algumas amostras estudadas. Esta tabela apresenta os dados de especiação apenas para os elementos encontrados nas amostras estudadas em concentrações acima dos seus respectivos limites de quantificação. As concentrações dos elementos citados referem-se a valores reais, sendo importante salientar que as concentrações de metais determinadas na solução de ácido húmico $100 \mathrm{mg} \mathrm{L}^{-1}$ provêm da contaminação da própria solução e do reagente utilizado. No entanto, estes dados indicam ser possível a análise de especiação em amostras reais contendo substâncias húmicas dissolvidas em alta concentração. Como pode se observar, uma fração significativa de alguns metais estudados se encontra na forma livre (biodisponível) nas amostras estudadas: $\mathrm{Zn}$ (II) de 16,56 a $85,36 \%, \mathrm{Cd}(\mathrm{II})$ de 51,85 a 59,09\%, Pb(II) de 35,00 a $75,38 \%$ e Al(III) de 14,37 a 43,96\%. Já na amostra de urina, a maior parte do Zn(II) se encontra na forma livre. No fluido pós-hemodiálise, mais da metade do Fe(III) excretado pelo paciente durante a diálise se encontra na forma livre ou fracamente ligado a compostos orgânicos.
Tabela 2. Análise de especiação química de metais nas amostras estudadas empregando determinação voltamétrica por ASV e AdCSV e irradiação UV $(n=3)$

\begin{tabular}{lccccc}
\hline Amostra & Metal & $\begin{array}{c}\text { Fração } \\
\text { livre } \\
\left(\mu \mathrm{g} \mathrm{L}^{-1}\right)\end{array}$ & $\begin{array}{c}\text { Concentração } \\
\text { total }^{b} \\
\left(\mu \mathrm{g} \mathrm{L}^{-1}\right)\end{array}$ & $\begin{array}{c}\text { Fração } \\
\text { combinada }^{c} \\
\left(\mu \mathrm{g} \mathrm{L}^{-1}\right)\end{array}$ & $\begin{array}{c}\text { \% Metal } \\
\text { livre }\end{array}$ \\
\hline Ácido & $\mathrm{Zn}$ & 25,79 & 33,79 & 8,00 & 76,32 \\
húmico & $\mathrm{Cd}$ & 0,13 & 0,22 & 0,09 & 59,09 \\
100 mg L-1 & $\mathrm{Pb}$ & 0,49 & 1,40 & 0,91 & 35,00 \\
& $\mathrm{Cu}$ & nd & 2,94 & 2,94 & 0,00 \\
Água do & $\mathrm{Zn}$ & 16,16 & 18,93 & 2,77 & 85,36 \\
mar & $\mathrm{Pb}$ & 0,98 & 1,30 & 0,32 & 75,38 \\
& $\mathrm{Cu}$ & 2,36 & 2,96 & 0,60 & 79,73 \\
& $\mathrm{Al}$ & 1,64 & 3,73 & 2,09 & 43,96 \\
& $\mathrm{Fe}$ & nd & 4,66 & 4,66 & 0,00 \\
Água de & $\mathrm{Zn}$ & 7,39 & 44,61 & 37,22 & 16,56 \\
córrego & $\mathrm{Cd}$ & 0,14 & 0,27 & 0,13 & 51,85 \\
(UFSM) & $\mathrm{Pb}$ & 0,81 & 1,25 & 0,44 & 64,80 \\
& $\mathrm{Cu}$ & nd & 3,89 & 3,89 & 0,00 \\
& $\mathrm{Al}$ & 4,91 & 34,15 & 29,24 & 14,37 \\
& $\mathrm{Fe}$ & 12,32 & 13,73 & 1,41 & 89,73 \\
Urina & $\mathrm{Zn}$ & 69,08 & 78,52 & 9,44 & 87,97 \\
humana & $\mathrm{Cd}$ & nd & 1,81 & 1,81 & 0,00 \\
Fluido pós- & $\mathrm{Zn}$ & nd & 13,56 & 13,56 & 0,00 \\
hemodiálise & $\mathrm{Pb}$ & 0,13 & 1,56 & 1,43 & 8,33 \\
& $\mathrm{Cu}$ & nd & 7,15 & 7,15 & 0,00 \\
& $\mathrm{Fe}$ & 4,01 & 6,54 & 2,53 & 61,31 \\
\hline
\end{tabular}

$\overline{{ }^{a} \operatorname{RSD}(n=3): 2-5 \% ;{ }^{b} \operatorname{RSD}(n=3): 2-4 \% ;{ }^{c} \text { Calculada: concentração }}$ total - fração livre ; ${ }^{d}$ não-detectado

Os resultados obtidos, além de comprovar a eficiência do sistema de irradiação construído para a destruição da matéria orgânica de diferentes amostras, demonstram a importância da etapa de decomposição das espécies orgânicas na avaliação da especiação química de metais em amostras de águas e fluidos biológicos.

\section{CONCLUSÕES}

Na primeira parte deste trabalho, a eficiência de mineralização das amostras de águas e fluidos biológicos com o sistema de irradiação UV construído em laboratório foi sistematicamente investigada, sendo que os tempos e as condições de irradiação UV para cada amostra foram otimizados. Este estudo demonstrou que a escolha das condições adequadas de mineralização empregando radiação UV depende fortemente do tipo de amostra a ser analisada. As adições de $\mathrm{H}_{2} \mathrm{O}_{2} 30 \%$ e $\mathrm{H}_{2} \mathrm{SO}_{4}$ concentrado, imediatamente antes do processo de irradiação UV, foram necessárias para a formação de radicais $\mathrm{HO}^{*}$ que possuem um alto potencial de oxidação e reagem com a matéria orgânica dissolvida na amostra. Devido aos pequenos volumes de $\mathrm{H}_{2} \mathrm{O}_{2}(50-200 \mu \mathrm{L}) \mathrm{e}$ $\mathrm{H}_{2} \mathrm{SO}_{4}(50 \mu \mathrm{L})$ adicionados às amostras, a mineralização de amostras com radiação UV diminui de maneira significativa a possibilidade de contaminação da amostra. A mineralização completa das amostras foi obtida após 2 h de irradiação UV, com exceção da amostra de urina que, além de ser necessária a renovação sucessiva de $\mathrm{H}_{2} \mathrm{O}_{2}$ a cada hora de irradiação, exigiu $4 \mathrm{~h}$ de irradiação UV para a eliminação total de sua cor e destruição completa da matéria orgânica dissolvida. Através da análise comparativa dos voltamogramas obtidos das amostras irradiadas e não-irradiadas, pode-se concluir que a destruição da matéria orgânica é etapa indispensável na determinação de traços metálicos por voltametria de redissolução (ASV e AdCSV). Além disso, o perfil dos espectros UV-Vis de amostras irradiadas e não-irradiadas confirma o comportamento observado nos voltamogramas de redissolução. O 
uso da radiação UV, como etapa prévia à determinação voltamétrica dos metais, permite a liberação do metal ligado à matriz orgânica e a determinação da concentração total dos elementos presentes nas amostras. A associação da medida voltamétrica direta dos metais ao pré-tratamento das amostras com radiação UV permite a análise de especiação dos metais nas amostras de águas, fluido pós-hemodiálise e urina humana. O sistema de irradiação construído elimina com grande eficiência os interferentes orgânicos presentes nas diferentes matrizes, com a vantagem adicional de ser de fácil construção, empregar material de fácil aquisição e ter um baixo custo de manutenção. Com relação ao custo do procedimento de pré-tratamento empregado neste trabalho em relação aos procedimentos tradicionais (digestão ácida convencional ou digestão ácida com aquecimento em forno de microondas), o baixo consumo de reagentes $\left(50-200 \mu \mathrm{L}\right.$ de $\mathrm{H}_{2} \mathrm{O}_{2} 30 \%$ e $50 \mu \mathrm{L}$ de $\mathrm{H}_{2} \mathrm{SO}_{4}$ concentrado) e o baixo custo da lâmpada de $\mathrm{Hg}$ de alta pressão (R $\$$ $80,00 \pm 20,00$ ) ilustram as vantagens do procedimento proposto no que se refere à construção do sistema e à sua manutenção. Além disso, o baixo consumo de reagentes reduz drasticamente a possibilidade de contaminação das amostras durante a etapa de pré-tratamento, uma vez que os metais a serem analisados e especiados se encontram, geralmente, em baixas concentrações.

\section{MATERIAL SUPLEMENTAR}

Está disponível em http://quimicanova.sbq.org.br, com acesso gratuito, na forma de arquivo em pdf.

A Figura 1S mostra a classe de compostos que sofrem decomposição pela radiação UV e seus sub-produtos.

A Figura 2S mostra o fluxograma experimental da determinação de metais empregando ASV e AdCSV com irradiação UV de amostras.

A Figura 3S mostra os espectros de absorção UV/Vis das amostras de ácido húmico $100 \mathrm{mg} \mathrm{L}^{-1}$, água modelo, fluido pós-hemodiálise e urina humana submetidas à irradiação UV.

A Figura 4S mostra o estudo da eficiência de mineralização das amostras de (a) água modelo, (b) água do córrego, (c) água do mar e (d) fluido pós-hemodiálise a partir de ensaios de recuperação dos metais $\left(25 \mu \mathrm{g} \mathrm{L}^{-1}\right)$ adicionados às amostras.

\section{REFERÊNCIAS}

1. Kolb, M.; Rach, P.; Schäfer, J.; Wild, A.; Fresenius J. Anal. Chem. 1992, 342,341 .

2. Locatelli, C.; Electroanalysis 2003, 15, 17.

3. van den Berg, C. M. G. Em Chemical Oceanography; Riley, J. P., ed.; Academic Press: London, 1988.

4. Campos, M. L. A. M.; Mello, L. C.; Zanette, D. R.; Sierra, M. M. S.; Bendo A.; Quim. Nova 2001, 24, 257.

5. Sodré, F. F.; Peralta-Zamora, P. G.; Grassi, M. T.; Quim. Nova 2004, 27, 695.

6. Achterberg, E. P.; Braungardt, C. B.; Sandford, R. C.; Worsfold, P. J.; Anal. Chim. Acta 2001, 440, 27.

7. Achterberg, E. P.; van den Berg, C. M. G.; Anal. Chim. Acta 1994, 291, 213.

8. Sander, S.; PhD Thesis, University of Kaiserslautern, Germany, 1995.

9. Golimowski, J.; Golimowska, K.; Anal. Chim. Acta 1996, 325, 111.

10. Yokoi, K.; Yakushiji, M.; Hatanaka, M.; Kubono, K.; Koide, T.; Fresenius J. Anal. Chem. 1999, 365, 364.

11. Rooney, R. C.; Melver, P. J.; Analyst 1962, 87, 895.

12. Sauer, D. Em Sample Preparation Techniques in Voltammetric Analysis; Bruttel, P. A.; Schäfer, J., eds.; Metrohm: Herisau, 1992.

13. Bisutti, I.; Hilke, I.; Raessler, M.; Trends Anal. Chem. 2004, 23, 716.

14. Zimmermann, S.; Menzel, C. M.; Berner, Z.; Eckhardt, J. D.; Stüben, D.; Alt, F.; Messerschmidt, J.; Taraschewski, H.; Sures, B.; Anal. Chim. Acta 2001, 439, 203. 
DETERMINAÇÃO VOLTAMÉTRICA DE METAIS EM ÁGUAS E FLUIDOS BIOLÓGICOS EMPREGANDO MINERALIZAÇÃO DE AMOSTRAS COM RADIAÇÃO ULTRAVIOLETA\#

Leandro M. de Carvalho*, Cristiane Spengler, Júlia C. Garmatz, Paulo C. do Nascimento, Denise Bohrer, Luciana DelFabro, Guilherme Radis e Antônio A. Bolli

Departamento de Química, Universidade Federal de Santa Maria, CP 5051, 97110-970 Santa Maria - RS, Brasil

Solange C. Garcia e Angela M. Moro

Departamento de Análises Clínicas e Toxicológicas, Universidade Federal de Santa Maria, 97110-970 Santa Maria - RS, Brasil

Marcelo B. da Rosa

Laboratório de Exobiologia e Biosfera, Centro Regional Sul de Pesquisas Espaciais, 97110-970 Santa Maria - RS, Brasil

\section{Componentes da amostra}

\section{Produtos finais}

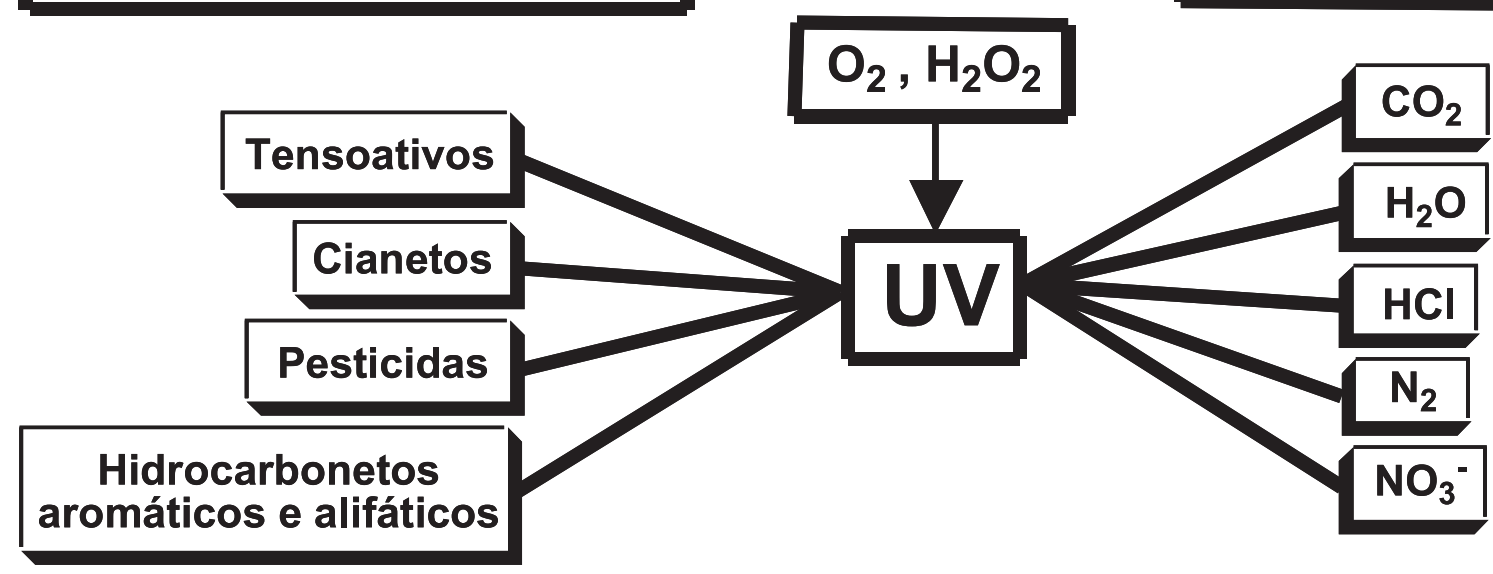

Figura 1S. Classe de compostos que sofrem decomposição pela radiação UV e seus sub-produtos 


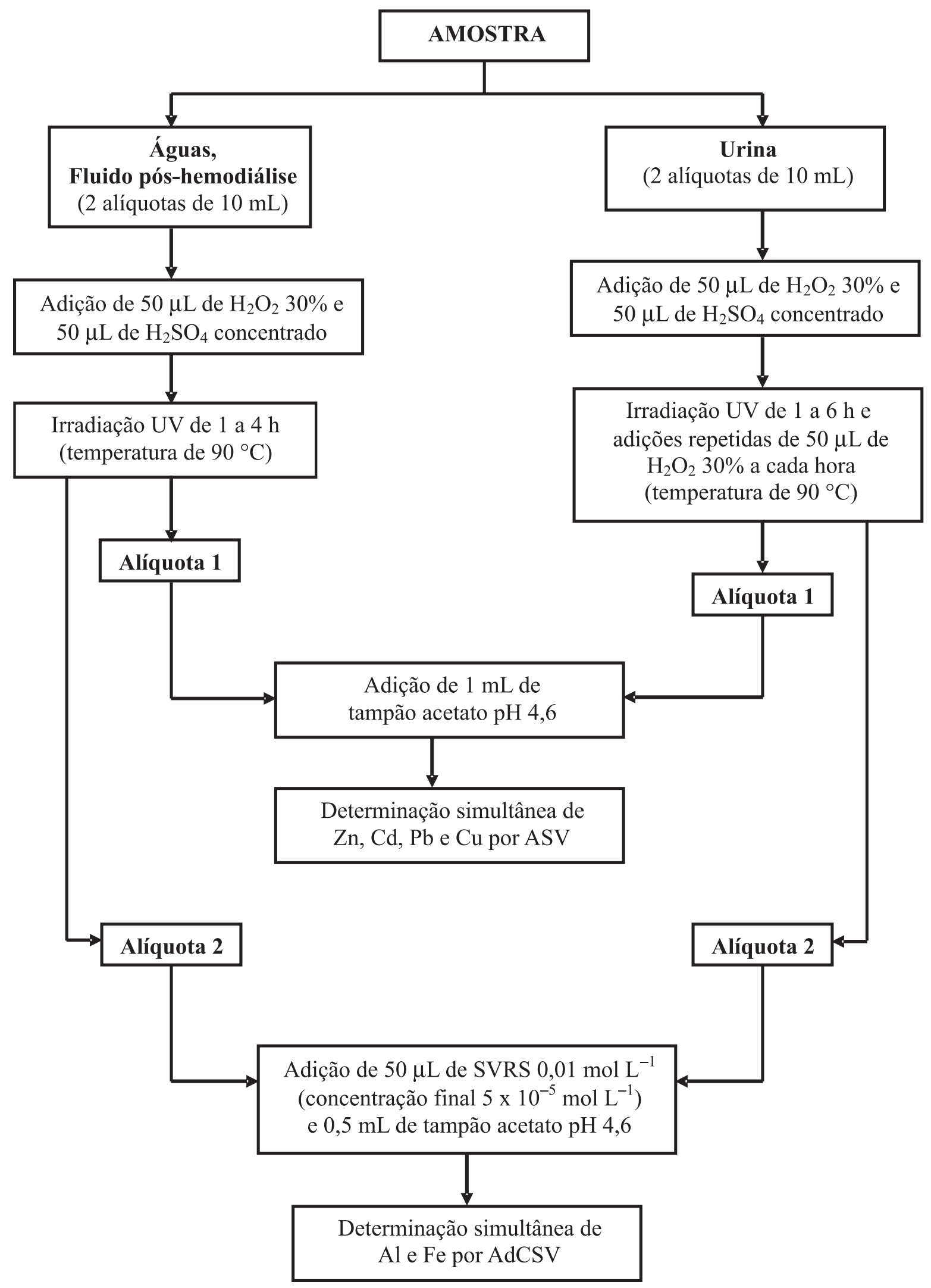

Figura 2S. Fluxograma experimental da determinação de metais empregando ASV e AdCSV com irradiação UV de amostras 
A
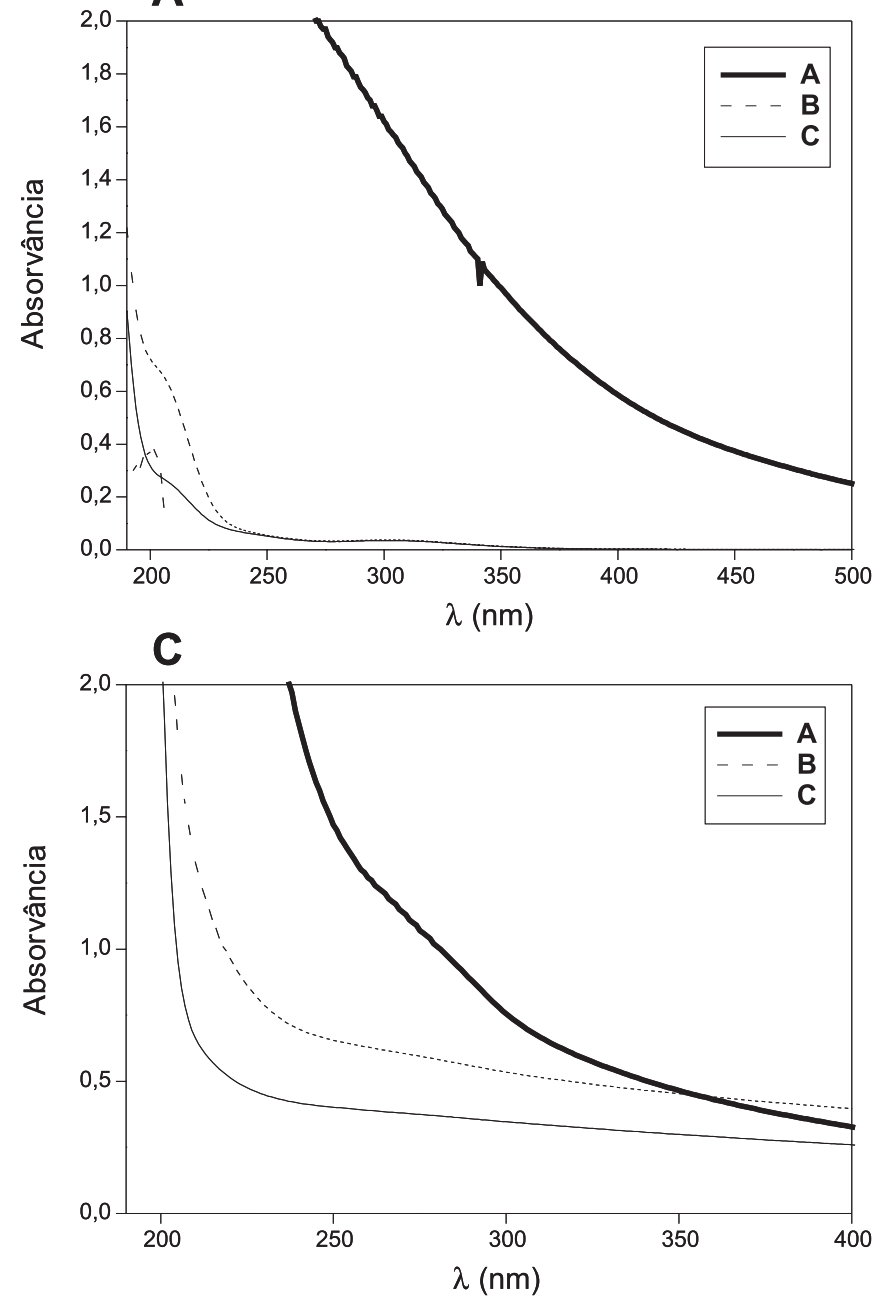

B
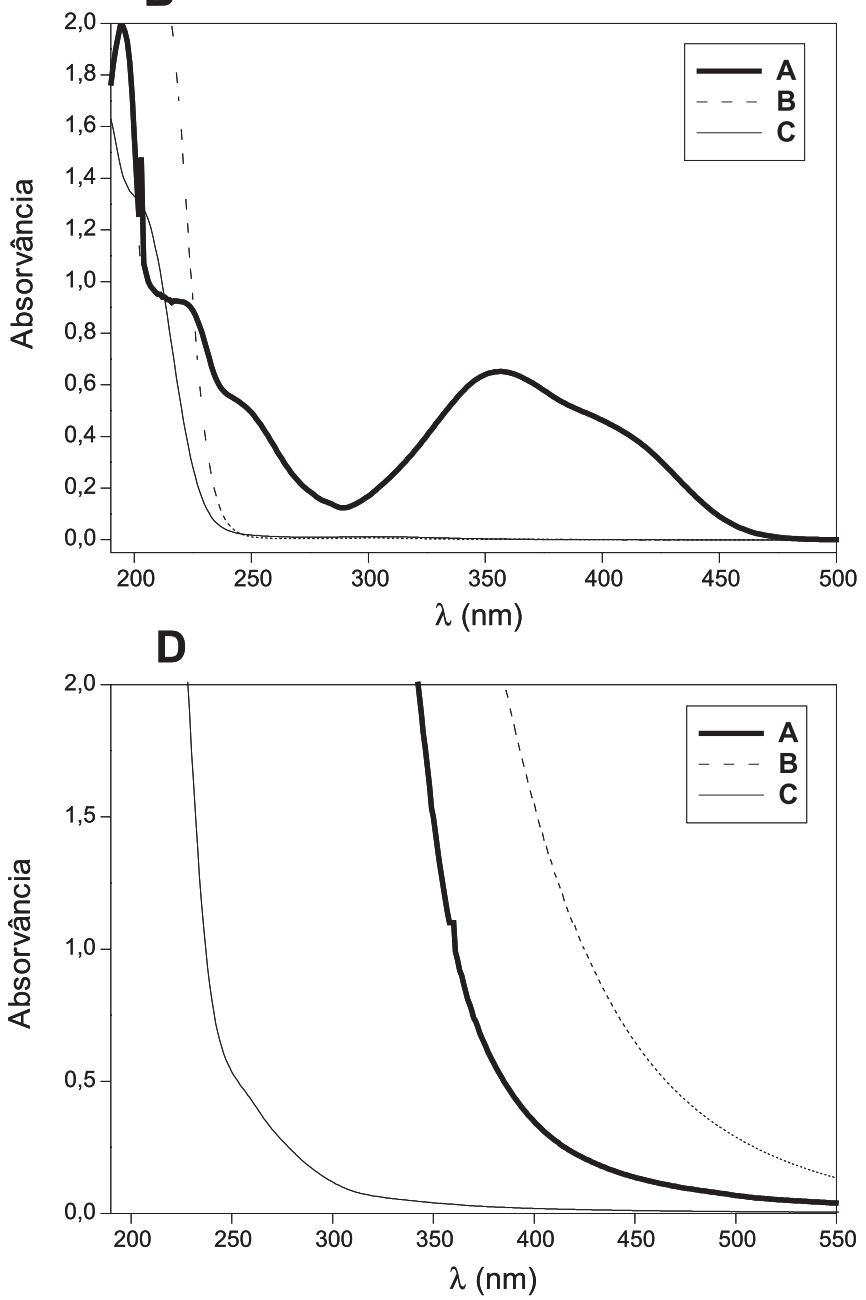

Figura 3S. Espectros de absorção UV/Vis das amostras de (A) ácido húmico $100 \mathrm{mg} L^{-1}$, (B) água modelo, (C) fluido pós-hemodiálise e (D) urina humana. Nas figuras, os espectros (A) referem-se a amostras não-irradiadas, (B) a amostras submetidas a 2 h de irradiação UV e (C) a amostras submetidas a 4 h de irradiação UV. Condições de irradiação: $50 \mu \mathrm{L}$ de $\mathrm{H}_{2} \mathrm{O}_{2} 30 \%$, $10 \mu \mathrm{L}$ de $\mathrm{H}_{2} \mathrm{SO}_{4}$ e $\mathrm{T}=90{ }^{\circ} \mathrm{C}$ para amostras de ácido húmico 100 mg L-1 água modelo e fluido pós-hemodiálise; 4 adições de $50 \mu \mathrm{L}$ de $\mathrm{H}_{2} \mathrm{O}_{2} 30 \%$ (no início e a cada hora de irradiação), $10 \mu \mathrm{L}$ de $\mathrm{H}_{2} \mathrm{SO}_{4}$ e $\mathrm{T}=90{ }^{\circ} \mathrm{C}$ para amostras de urina humana 
A

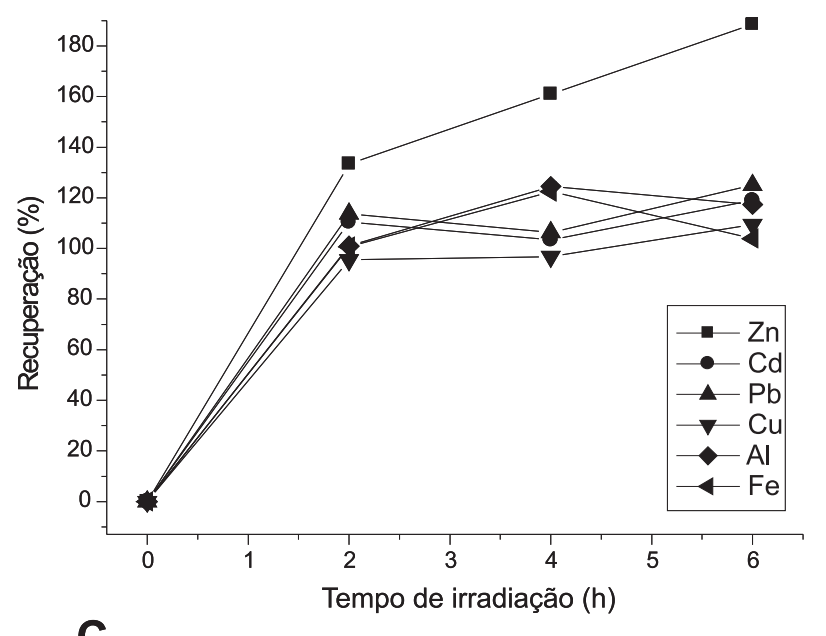

C

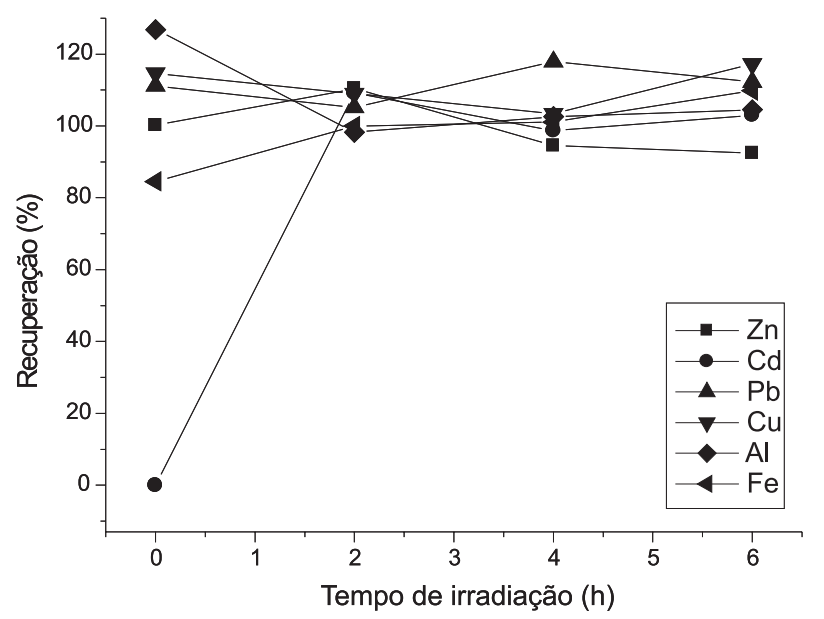

B

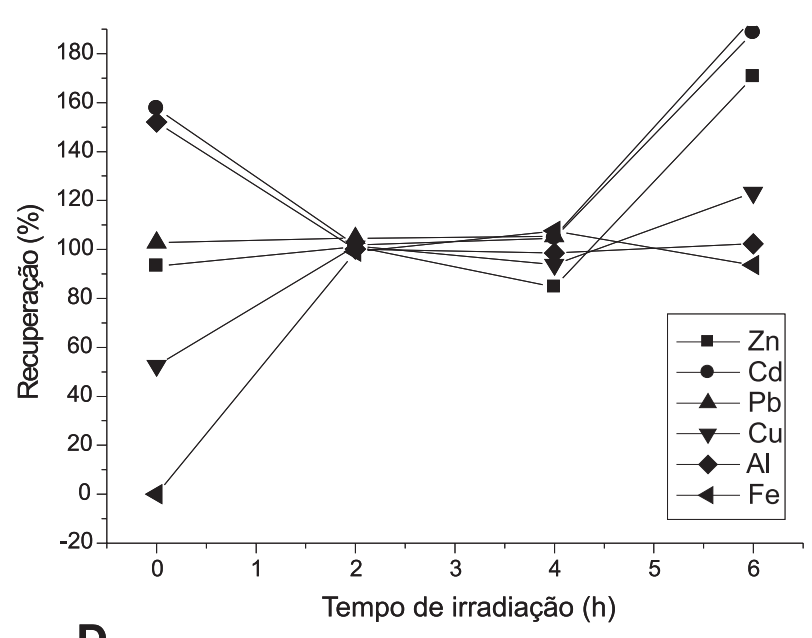

D

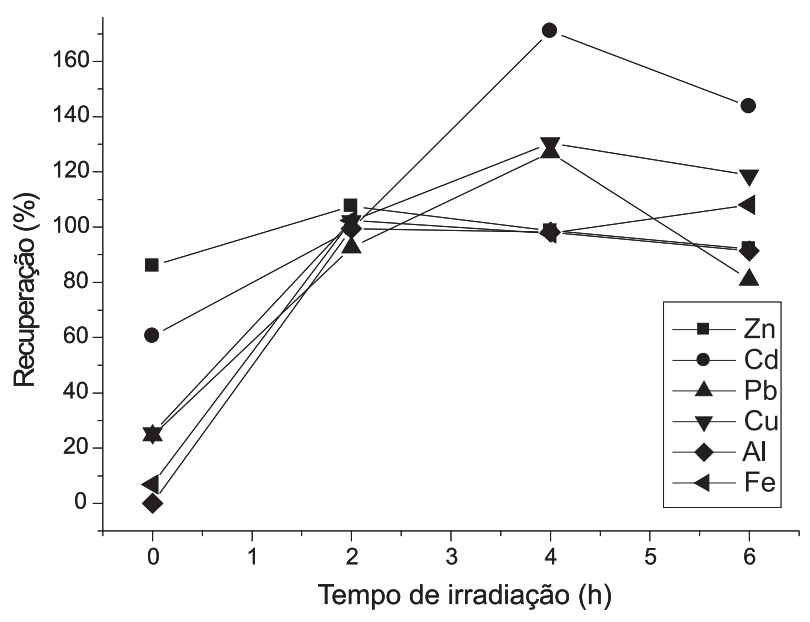

Figura 4S. Estudo da eficiência de mineralização das amostras de (A) água modelo, (B) água do córrego, (C) água do mar e (D) fluido pós-hemodiálise a partir de ensaio de recuperação dos metais $\left(25 \mu \mathrm{g} \mathrm{L}^{-1}\right)$ adicionados às amostras. As determinações dos metais por ASV foram realizadas pelo método da adição do padrão $(\mathrm{n}=3)$. Condições da irradiação: como descrito na Figura $2 S$ 